\title{
Effectiveness of advanced coating systems for mitigating blast effects on steel components
}

\author{
C. Chen ${ }^{1}$, D. G. Linzell ${ }^{1}$, E. Alpman ${ }^{2}$ \& L. N. Long ${ }^{3}$ \\ ${ }^{I}$ Department of Civil and Environmental Engineering, \\ The Pennsylvania State University, USA \\ ${ }^{2}$ Department of Mechanical Engineering, Marmara University, Turkey \\ ${ }^{3}$ Department of Aerospace Engineering, \\ The Pennsylvania State University, USA
}

\begin{abstract}
The objective of this work is to study the effectiveness of an advanced coating material, polyurea, as a blast mitigation tool for steel components. The response of polyurea coated steel components under blast loading is studied using the explicit LS-DYNA code with appropriate loading time histories supplied using a computational fluid dynamics (CFD) code developed at Penn State University, PUMA2 (Parallel Unstructured Maritime Aerodynamics-2).

Results presented from this ongoing research study are related to an application of polyurea onto armor grade steel plates and an examination of resulting failure modes and governing design parameters. Failure modes examined herein consist of fracturing in the polyurea/steel composite structure. Effects of thicknesses and locations of the polyurea on the blast mitigation are also studied. Explanations of selected strain-rate dependent material models for the steel and polyurea are provided. CFD blast simulations using PUMA2 are described and validated. Results obtained from numerical studies completed to date show that bare steel plate experiences severe fracturing and fragmentation under prescribed blast loading while polyurea coated plates are able to sustain prescribed pressures without fully fracturing.
\end{abstract}

Keywords: polyurea, armor steel, blast, finite element, computational fluid dynamics. 


\section{Introduction}

With the growing concerns that terrorists may use Improvised Explosive Devices (IEDs) against American security and infrastructure interests, the need to protect many types of structures against blast and impact loads generated by these types of devices continues to be an extremely important issue. Conventional structures that are primarily designed based on strength and serviceability criteria are generally quite vulnerable to blast loads and require more ductility. In addition, the continued advancement of IEDs and the subsequent increase in their potency makes even conventionally hardened structural systems more vulnerable to blast events. Therefore, new design criteria and new materials that are intended to resist blast loads have to be developed to provide sufficient strength and ductility.

Polyurea, a relatively new material for civil infrastructure applications, has drawn the interest of researchers recently. Polyurea is an elastomer created by a chemical reaction between an isocyanate and an amine. Past public domain research appears to indicate that polyurea is an efficient retrofitting material against blast loads for masonry wall systems [1] used in residential or low-rise office structures. Other work indicates that polyurea can be sprayed on as an explosive resistant coating for steel plates [2]. Application of polyurea to other types of structural components and systems continues to receive interest. Substrate materials used with polyurea can vary widely with respect to their behavior, from brittle or pseudo-ductile concrete and timber framed structures to ductile steel framed systems to architecturally clad structures. As such, the approach for designing an effective polyurea coating system for rehabilitating each material to make it more robust against blast events differs, as well. While numerous researchers have examined the behavior of bare steel plates subjected to impact and blast loadings, public domain research related to polyurea coated metals that focuses on failure modes and performance parameters is limited [3-7]. Research outlined herein is attempting to examine general performance characteristics and failure modes of polyurea on steel components.

\section{Materials and material models}

American Iron and Steel Institute (AISI) 4340 steel is selected as the substrate material for the current study; it is a material used for aircraft and truck parts and armoring systems and is commonly used by researchers for impact and blast studies. AISI 4340 steel is normally heat treated by quenching in oil and tempering to the desired hardness. As was stated earlier, Polyurea, an elastomer created by the chemical reaction between an isocyanate and an amine, is selected as the coating material.

Materials subjected to impact/blast loading behave differently from those under static loading. Therefore, to simulate structural behavior under high strain rates, constitutive models with strain rate dependency are necessary for material modeling. The Johnson-Cook material model [8], which is capable of modeling large strains, high strain rates, and high temperatures, was selected to model steel 
response under air blasts. This material model is widely used and validated for various metals under high strain rate loading conditions [3-7]. The expression of the flow stress for the Johnson-Cook material model is [8]:

$$
\left.\sigma=\left\lfloor A+B\left(\varepsilon^{p l}\right)^{n}\right\rfloor 1+C \ln \left(\dot{\varepsilon}^{*}\right)\right]\left[1-T^{* m}\right]
$$

where $\varepsilon^{p l}$ is the effective plastic strain, $\dot{\varepsilon}^{*}$ is the normalized effective plastic strain rate, $\mathrm{n}$ is the work hardening exponent, and $\mathrm{A}, \mathrm{B}, \mathrm{C}$, and $\mathrm{m}$ are material constants. $\mathrm{T}^{*}$ equals:

$$
T^{*}=\frac{T-T_{\text {room }}}{T_{\text {melt }}-T_{\text {room }}}
$$

where: $\mathrm{T}$ is the absolute temperature, $T_{\text {room }}$ is the room temperature, and $T_{\text {melt }}$ is the melting temperature. Terms in the first bracket of eqn. (1) account for strain hardening effects; terms in the second bracket account for strain rate effects; and terms in the final bracket account for temperature effects. Material parameters (A, B, C, n, and $\mathrm{m}$ ) for AISI 4340 steel can be readily found in the literature $[5,9-11]$, and are tabulated in table 1 . In this study, parameters for the Johnson-Cook material model are selected from [5]. $(\mathrm{A}=792 \mathrm{MPa}, \mathrm{B}=510 \mathrm{MPa}$, $\mathrm{C}=0.014, \mathrm{n}=0.26$, and $\mathrm{m}=1.03$ ).

Table 1: Johnson-Cook material parameters [5, 9-11].

\begin{tabular}{cccccc}
\hline $\mathrm{A}(\mathrm{MPa})$ & $\mathrm{B}(\mathrm{MPa})$ & $\mathrm{C}$ & $\mathrm{n}$ & $\mathrm{M}$ & $\mathrm{T}_{\text {melt }}(\mathrm{K})$ \\
\hline $729 \sim 792$ & $473 \sim 676$ & 0.014 & 0.26 & 1.03 & $1720 \sim 1793$ \\
\hline
\end{tabular}

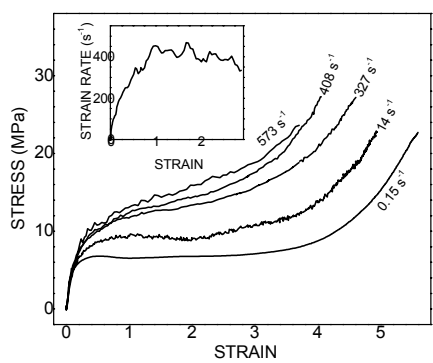

Figure 1: $\quad$ Engineering stress vs. strain curves for various strain rates [13].

Recent experimental studies of polyurea behavior under varying strain rates observe that the material's response is highly nonlinear and strongly strain rate dependent $[12,13]$. In the work summarized herein, the polyurea was 
preliminarily modeled using LS-DYNA Material Type 112 with performance input provided from previously published high strain rate tensile testing data (fig. 1) [13]. Stress-strain curves for a broad range of rates could be defined by LSDYNA users using this elasto-plastic material model. The user-defined stressstrain curves available via the Material Type 112 model and test data made the model rate dependent and able to be tailored to fit the highly nonlinear behavior of the polyurea.

\section{Numerical program}

The ongoing numerical program was designed to investigate air blast effects on polyurea coated steel plates. The numerical model that was examined consisted of a steel plate with or without polyurea coating subjected to blast loading caused by TNT placed 1 meter away from the center of the plate. Dimensions of the steel plate were fixed at $1.5 \mathrm{~m} \times 1.5 \mathrm{~m} \times 0.635 \mathrm{~cm}$, and thicknesses of the polyurea coating were $0.635 \mathrm{~cm}, 1.27 \mathrm{~cm}, 1.905 \mathrm{~cm}$, and $2.54 \mathrm{~cm}$. All the edges of the plate were restrained against transverse and rotational deformations, and the coating was placed onto the back (away from the air blast), front, or both sides of the plate. To solve this problem an uncoupled approach was utilized that incorporated CFD analyses for blast simulations and explicit finite element analyses for responses of the structure when acted upon by the pressure timehistories from the CFD runs. The computational fluid dynamics (CFD) analyses were performed using an in-house code, PUMA2, and finite element analyses were accomplished utilizing LS-DYNA.

\subsection{CFD analyses}

PUMA2 simulated blast waves by solving Euler equations with no viscous flow effects. For the blast simulations, the explosive was assumed to be spherical in shape and was modeled as $34 \mathrm{~kg}$ of TNT with the density of $1500 \mathrm{~kg} / \mathrm{m}^{3}$. The explosive was placed at a 1 meter standoff distance, measured from the surface of the plate to the center of the explosive, from the steel. Pressure time-histories were then provided over the surface of the plate with the plate being represented as a rigid boundary. These time-histories were then used as input applied to the LS-DYNA plate model to present the blast loads. Air blast pressure contours from the simulations are shown in fig. 2. The plate is represented as a black vertical line at the center of the right boundary. The contours indicated that the plate experienced positive pressures caused by the explosion, then negative pressures, and finally secondary positive shock waves after the negative phase. Fig. 3 shows the PUMA2 pressure time-history at the center of the plate. If the solution from PUMA2 for the peak pressure at this location is compared with results generated by ConWep [14], an empirically based program developed to calculate blast effects from prescribed charge weights and scaled distances, comparable results exist. Peak reflected pressures predicted by PUMA2 and ConWep for the parameters examined herein were $14.3 \mathrm{ksi}$ and $12.0 \mathrm{ksi}$, respectively. 


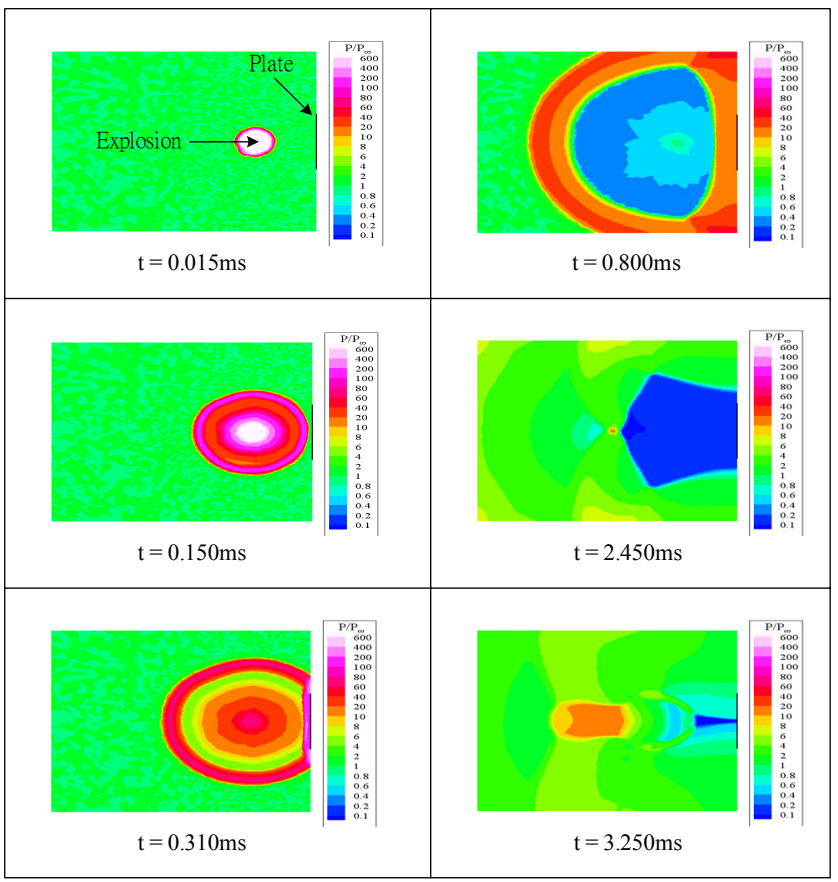

Figure 2: $\quad$ PUMA2 pressure contours at different times after detonation.

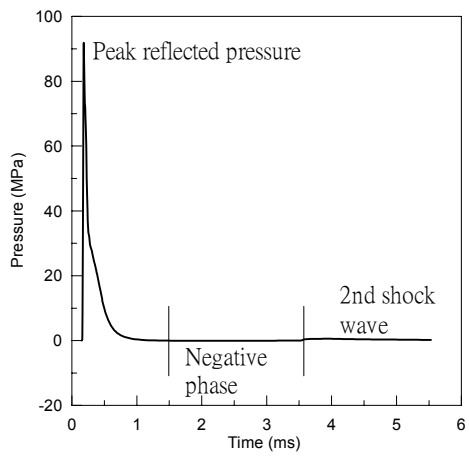

Figure 3: $\quad$ PUMA2 pressure time-history at center of the plate.

\subsection{Finite element analysis}

For the LS-DYNA analyses a total of 18,000 elements were created for both the steel plate and the polyurea coating. An 8-node brick element with one integration point was used for both the steel and polyurea, and for both the steel and polyurea the thickness of a brick element was $0.0635 \mathrm{~cm}$, i.e. ten elements through the thickness of the steel plate. For results reported herein the polyurea and steel were assumed to be perfectly bonded. Material models were as 
discussed in the previous section. Fracture criteria were based on failure strains observed from material tests and reported experimental results [13] for the steel and polyurea, respectively. Blast loads were applied using a total of 3,600 individual pressure time-histories over the plate surface to represent threedimensional characteristics obtained from PUMA2. The plate was clamped on all edges in the analyses.

\subsection{Parametric study}

This section examined effects of the polyurea thickness, steel thickness, and coating location on the response of the steel plate under blast loading. Table 2 details the parametric study matrix.

Table 2: $\quad$ Parametric study matrix.

\begin{tabular}{|c|c|c|c|c|}
\hline Model & $\begin{array}{c}\text { Thickness of } \\
\text { steel }(\mathrm{cm})\end{array}$ & $\begin{array}{l}\text { Thickness of } \\
\text { polyurea }(\mathrm{cm})\end{array}$ & Location & Comment \\
\hline 1 & 0.635 & - & - & \\
\hline 2 & 0.635 & 0.635 & Back & $\begin{array}{c}\text { Same weight as } \\
\text { model } 6\end{array}$ \\
\hline 3 & 0.635 & 1.27 & Back & $\begin{array}{c}\text { Same weight as } \\
\text { model } 7\end{array}$ \\
\hline 4 & 0.635 & 1.905 & Back & $\begin{array}{c}\text { Same weight as } \\
\text { model } 8\end{array}$ \\
\hline 5 & 0.635 & 2.54 & Back & $\begin{array}{c}\text { Same weight as } \\
\text { model } 9\end{array}$ \\
\hline 6 & 0.7215 & - & - & \\
\hline 7 & 0.8080 & - & - & \\
\hline 8 & 0.8945 & - & - & \\
\hline 9 & 0.9810 & - & - & \\
\hline 10 & 0.635 & 0.635 & Front & \\
\hline 11 & 0.635 & 0.3175 & Both sides & \\
\hline
\end{tabular}

\section{Results}

Results of the finite element analysis are discussed in this section. As shown in table 2, a total of 11 models were examined. The highest pressure caused by the explosion occurred at $0.19 \mathrm{msec}$, and the simulations were terminated 0.01 second after initiation of the detonation. Maximum displacement and induced kinetic energy from the analyses were parameters utilized for evaluation of specimen response. Fig. 4 shows final deformed shapes from the analyses. Models of plain steel plates were fully fractured at all support corners with the exception of model 9 (two corners), and rigid body motion and fragmentation were observed from all uncoated analyses. For models 2 to 5, although the polyurea coating was not completely fractured at the corners, severe fractures were observed along the edges. For models 4 and 5, minor fractures were observed in the polyurea; however, full fractures in the steel at the corners were still observed. Displacements at the center of the plate and induced kinetic 


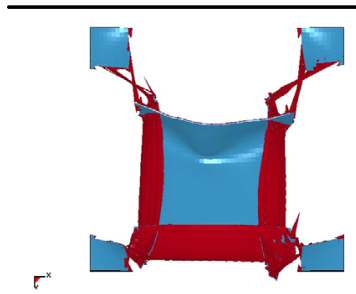

(a) model 2

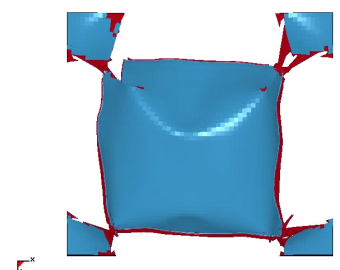

(c) model 3

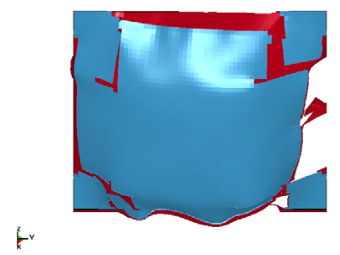

(e) model 4

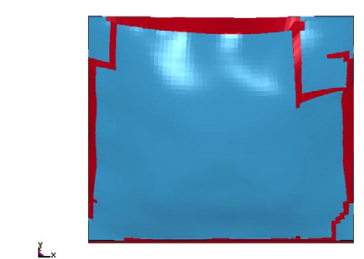

(g) model 5

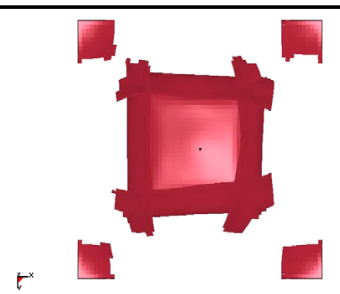

(b) model 6

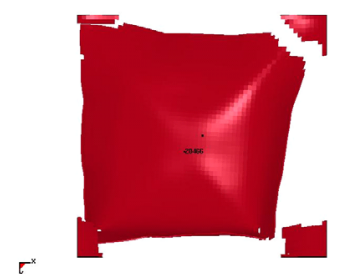

(d) model 7

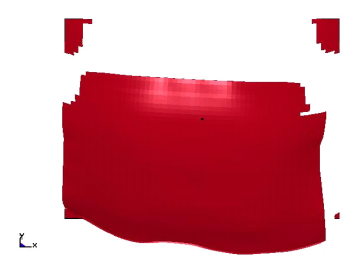

(f) model 8

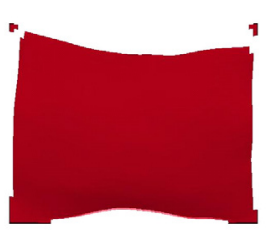

(h) model 9

Figure 4: $\quad$ Final deformed shapes.

energies at completion of the analyses $(\mathrm{t}=0.01 \mathrm{sec})$ are tabulated in table 3 and shown in fig. 5. The results showed that there was no apparent difference between maximum displacements with altered coating locations. However, the plate with the coating on the top possessed the least kinetic energy compared to the plates coated on the back or on both sides. To effectively understand the effectiveness of increasing polyurea thickness (models 2-5) these models were compared to models where steel thickness was increased to match the weights of coated plate models. For model 3, although the polyurea thickness was increased to $1.27 \mathrm{~cm}$, it had a larger displacement than the $0.808 \mathrm{~cm}$ thick steel plate 
Table 3: Deflections and kinetic energies.

\begin{tabular}{ccc}
\hline Model & Deflection $(\mathrm{m})$ & Kinetic energy $(\mathrm{N}-\mathrm{m})$ \\
\hline \hline 1 & 1.2371 & $6.49 \mathrm{E}+05$ \\
2 & 0.9858 & $3.33 \mathrm{E}+05$ \\
3 & 0.7625 & $1.25 \mathrm{E}+05$ \\
4 & 0.4270 & $1.73 \mathrm{E}+04$ \\
5 & 0.2972 & $1.95 \mathrm{E}+04$ \\
6 & 1.0287 & $4.32 \mathrm{E}+05$ \\
7 & 0.6858 & $2.07 \mathrm{E}+05$ \\
8 & 0.4902 & $1.15 \mathrm{E}+05$ \\
9 & 0.2946 & $1.69 \mathrm{E}+04$ \\
10 & 0.9841 & $2.63 \mathrm{E}+05$ \\
11 & 0.9815 & $3.07 \mathrm{E}+05$ \\
\hline
\end{tabular}
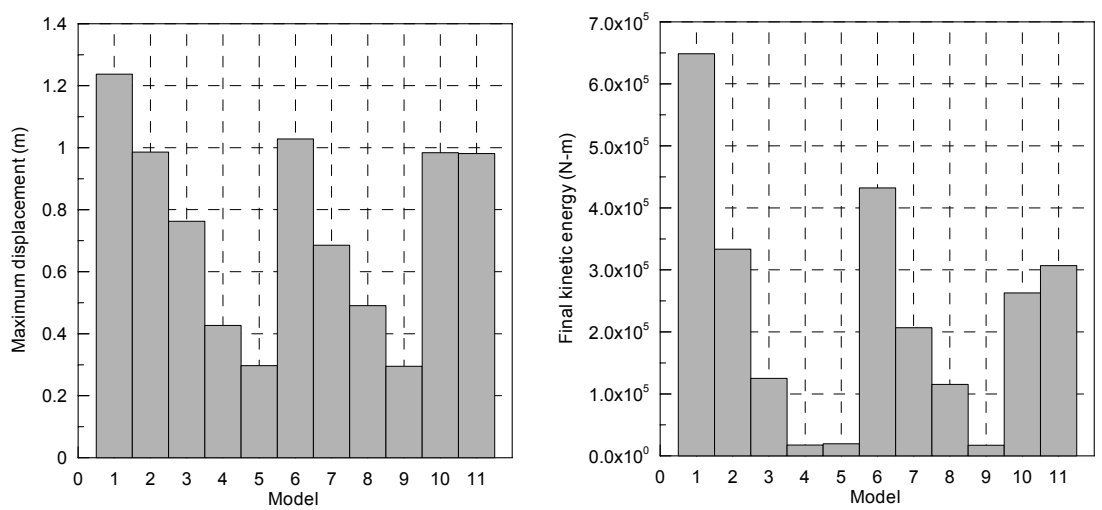

Figure 5: Displacement and kinetic energy at $0.01 \mathrm{sec}$.
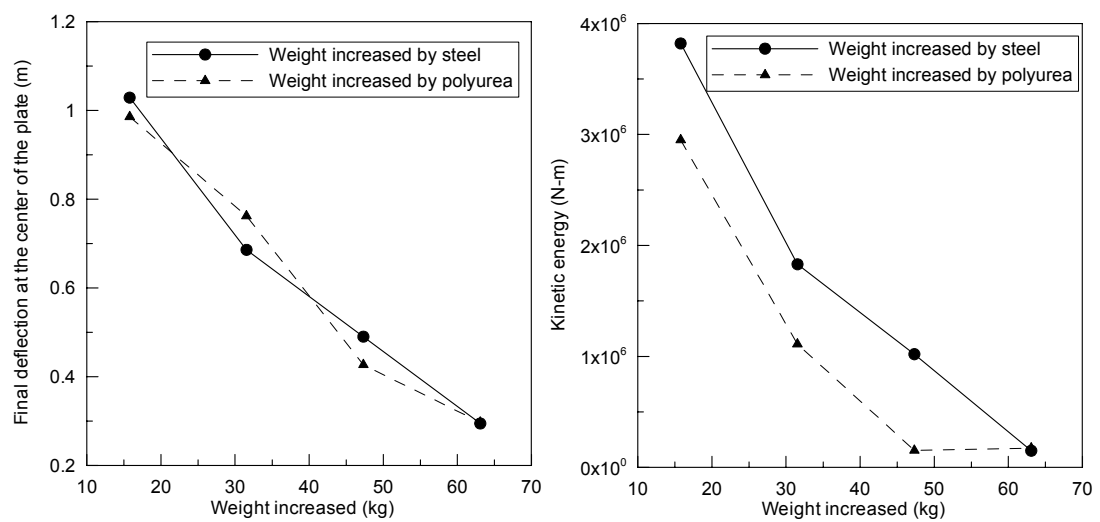

Figure 6: Deflections and kinetic energies for coated and uncoated plates. 
(model 7) having a similar weight, but the kinetic energy of model 3 was lower than that of model 7. When the polyurea thickness was increased to $1.905 \mathrm{~cm}$ (model 4), both the displacement and kinetic energy were lower than those of the $0.8945 \mathrm{~cm}$ thick steel plate (model 8) having a similar weight. However, when the polyurea thickness was increased to $2.54 \mathrm{~cm}$, the effectiveness of increasing polyurea was not as prominent as lighter cases when compared to 0.9810 steel plate (model 9) having a similar weight (see fig. 6).

\section{Conclusion}

Results of this ongoing study suggest that increasing weight by thickening polyurea is more efficient for absorbing energy and preventing fragmentation then increasing steel thickness alone. However, there is a limit for polyurea effectiveness based on deflection and kinetic energy. An optimal thickness ratio between the polyurea and steel is required to ensure the structure integrity for a prescribed loading should be identified. When perfect bond is assumed, the location of the polyurea coating relative to the blast loads is not critical to the maximum displacement, but it affects induced kinetic energy. Present results indicate that applying polyurea to the side subjected to the blast loading is preferred. However, bond between the polyurea and steel may fail under the blast loading, which could affect these findings. Therefore, bond strength between the polyurea and steel must be evaluated during design. The effects of bond strength on polyurea failure modes for coated steel plates are being examined, along with previously studied parameters, as part of this research program.

\section{Acknowledgements}

This study is funded by the U.S. Office of Naval Research grant no. ONR N00014-05-1-0844. The authors wish to thank Dr. C.M. Roland from the U.S. Naval Research Laboratory for providing experimental data used in the study.

\section{References}

[1] Davidson JS, et al. Explosive testing of polymer retrofit masonry walls. Journal of Performance of Constructed Facilities 2004; 18(2): 100-106.

[2] Amini MR, Isaacs JB, Nemat-Nasser S. Effect of polyurea on the dynamic response of steel plates. Proceedings of the 2006 SEM Annual Conference and Exposition on Experimental and Applied Mechanics. Saint Louis (MO, United States), 2006. p. 1323-1326.

[3] Gupta NK, Iqbal MA, Sekhon GS. Experimental and numerical studies on the behavior of thin aluminum plates subjected to impact by blunt- and hemispherical-nosed projectiles. Int J Impact Eng 2006; 32: 1921-1944.

[4] Børvik T, et al. Experimental and numerical study on the perforation of AA6005-T6 panels. Int J Impact Eng 2005; 32: 35-64. 
[5] Kurtaran H, Buyuk M, Eskandarian A. Design automation of a laminated armor for best impact performance using approximate optimization method. Int J Impact Eng 2003; 29: 397-406.

[6] Roeder BA, Sun CT. Dynamic penetration of alumina/aluminum laminates: experiments and modeling. Int J Impact Eng 2001; 25: 169-185.

[7] Børvik T, et al. Ballistic penetration of steel plates. Int J Impact Eng 1999; 22: $855-886$.

[8] Johnson GR, Cook WH. A constitutive model and data for metals subjected to large strains, high strain rates and high temperatures. Proceedings of seventh international symposium on ballistics. The Hague, 1983.

[9] Zukas JA, Walters WP. Explosive effects and application. Maryland, Springer-Verlag New York, Inc. 1998.

[10] Fuentes D, et al. Extensions of goal-oriented error estimation methods to simulations of highly-nonlinear response of shock-loaded elastomerreinforced structures. Computer Methods in Applied Mechanics and Engineering 2006; 195(37-40): 4659-4680.

[11] Littlefield D. The penetration of steel targets in radial extent. Int J Impact Eng 1997; 19: 49-62.

[12] Sarva SS, et al. Stress-strain behavior of a polyurea and a polyurethane from low to high strain rates. Polymer 2007; 48: 2208-2213.

[13] Roland CM, et al. High strain rate mechanical behavior of polyurea. Polymer 2007; 48: 574-578.

[14] Hyde DW. Conventional weapons effects computer program, US Waterways Experiment Station Instructional Report SL-88-1. US Army Corps of Engineers, 1992. 